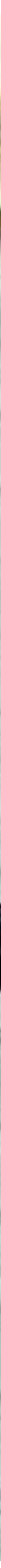

MARÍA DEL MAR FERNÁNDEZ ROBLES | ENRIQUE PASTOR SELLER | ANA CRISTINA RUIZ MOSOUERA | MARÍA DE LAS OLAS PALMA GARCÍA JUAN CARLOS ÁLVAREZ CORTÉS | HELENA NEVES ALMEIDA | BIBIANA ESPERANZA CHIQUILLO | SARA DE LA PINTA PRIETO RAFAEL ACEBES VALENTÍN | MÓNICA LISET VALBUENA PORRAS | LINA MARÍA PINZÓN ROCHA | LOURDES MORO GUTIÉRREZ MARÍA JESÚS PENA CASTRO | MARÍA FIOL RUIZ | YURI ALICIA CHÁVEZ PLAZAS | ALBA STELLA CAMELO MAYORGA | EVA ALADRO VICO MARÍA JOSÉ CAVADAS GORMAZ | DIMITRINA JIVKOVA SEMOVA | GRACIELA PADILLA CASTILLO | ROXANA POPELKA SOSA PAULA REQUEIJO REY | JOAQUÍN CASTILLO DE MESA | Ma INMACULADA LÓPEZ NÚÑEZ | JOSE MANUEL VELASCO RETAMOSA JORGE GARCÍA | SUSANA RUBIO VALDEHITA | BELÉN PEYRÓ OUTEIRIÑO | MIGUEL DEL FRESNO GARCÍA | LIANNE URADA 


\title{
Inmigrantes latinoamericanas en Salamanca: estudio de experiencias
} V CASOS

\section{Latin american women migrants in Salamanca: study of experiences}

\author{
Lourdes Moro Gutiérrez, María Jesús Pena Castro**, María Fiol Ruiiz ${ }^{* * *}$ \\ * Profesora Titular de Universidad. Departamento de Psicología Social y Antropología. Facultad de Psicología. \\ Universidad de Salamanca.moro@usal.es \\ ** Profesora Contratada Doctora. Departamento de Psicología Social y Antropología. Facultad de Geografía e Historia. \\ Universidad de Salamanca.mpena@usal.es \\ *** Trabajadora Social. Máster en Antropología Aplicada: Salud y Desarrollo Comunitario. maria_fiol@hotmail.com
}

\begin{abstract}
:
This paper analyses the migration process of a group of Latin American women to Salamanca (Spain) from the socio-cultural consideration. Through qualitative interviewing and case study, the research team explored from a gender perspective their migration and adaptation processes: motivations for emigration, the previous expectations, difficulties in the process, as well as the recollection of the diversity of places they occupied in society, regarding to physical spaces, power, participation or communication. The results achieved show a positive perception of their transit, looking for personal and family well-being, despite of the numerous changes they had faced and the difficulties encountered.
\end{abstract}

Keywords: Migration process, Gender, Socio-cultural Analysis, Well-being.

\section{Resumen:}

Este trabajo propone analizar desde la perspectiva sociocultural el proceso migratorio de un grupo de mujeres latinoamericanas que han emigrado a Salamanca (España). A través de entrevistas cualitativas en profundidad y el estudio de casos se investigan desde una perspectiva de género sus procesos migratorios y de adaptación en el lugar de destino: cuáles han sido las razones que las han impulsado a emigrar, sus expectativas previas y las dificultades que se han encontrado en el proceso, además de identificar los espacios materiales, de poder, participación y comunicación que ocupan en la sociedad. Los resultados obtenidos indican una percepción positiva de su tránsito en busca de la mejora de su bienestar personal y familiar a pesar de los numerosos cambios que han debido afrontar y de las dificultades encontradas.

Palabras clave: Género, proceso migratorio, análisis sociocultural, bienestar. 


\section{Article info:}

Received: 02/02/2017 / Received in revised form: 26/10/2017

Accepted: 19/01/2018 / Published online: 30/01/2018

DOI: http://dx.doi.org/10.5944/comunitania.15.7

\section{Introducción}

\subsection{La influencia del género en los procesos migratorios}

Nuestro trabajo pretende dar voz a la mujer inmigrante latinoamericana con el objetivo de conocer sus experiencias desde una perspectiva de género. Para ello realizamos un análisis de casos mediante entrevistas cualitativas en profundidad a 14 mujeres latinoamericanas que residen en Salamanca (España). Nos preguntamos por las razones que las impulsan a emigrar, sus expectativas previas y las dificultades que se han encontrado en el proceso. Pretendemos identificar los espacios físicos, de poder, participación y comunicación que ocupan en la sociedad.

España sigue siendo uno de los países con mayor recepción de inmigración procedente de Latinoamérica, aunque el ritmo de crecimiento se ha detenido debido a la situación de crisis económica global. Colombia y la República Dominicana son los países con más flujo migratorio a España, seguidos por Honduras, Venezuela y Brasil. Respecto a Salamanca residen 6116 mujeres con nacionalidad extranjera de las cuales 3380 son latinoamericanas. El país con mayor presencia es Colombia (602 mujeres), seguido de Bolivia (451), Perú (390), República Dominicana (351), Brasil (243) y Ecuador (242). Con respecto a los hombres residen en Salamanca 5055, de los cuales 2466 son latinoamericanos (INE 2015).

Los primeros estudios sobre migración no consideraban a las mujeres como posibles migrantes o si lo hacían, era como acompañantes del hombre. Las mujeres representaban la inmigración pasiva o inducida. No es hasta la década de los años 80, con autoras como Morokvasic y Phizacklea, cuando comienza a plantearse la importancia de las relaciones de género como factor fundamental en el proceso migratorio. En la actualidad son reconocidas como protagonistas de la migración y como responsables de importantes proyectos económicos y sociales. Se ha producido una feminización de la migración como proceso global. Esto lleva aparejado que también se haya incrementado el interés por conocer cómo se ve afectada la familia por la migración, añadiendo una perspectiva transnacional en los estudios (Bermúdez 2004; Padilla 2013; Bastia 2014; Bravo y Caparrós 2015; Hernández 2015). La emigración se constituye, por tanto, como una estrategia más de mantenimiento y reproducción de los grupos domésticos (Gregorio 1998; Pedone 2002; Oso 2008).

El género constituye un factor importante en la experiencia migratoria que influye en las decisiones de cuándo, quién y dónde emigrar, en función de los roles y las 
responsabilidades asociadas. Conceder el permiso para emigrar, facilitar recursos para ello y establecer expectativas de contribución al mantenimiento de la familia, están ligadas al género (Canales y Zlolniski 2000; Bastia 2009; Bravo y Caparrós 2015). En muchas ocasiones, las migraciones internacionales surgen como una estrategia del grupo doméstico, es un proyecto de inversión familiar en el que todos deciden conjuntamente quién lo lleva a cabo, cómo se va a realizar, el reparto de remesas y el cuidado de las personas que se quedan en el país de origen. El grupo doméstico ya no se entiende como el grupo de individuos que residen juntos, sino que adquiere un carácter transnacional, entendido como un grupo de personas que asegura su mantenimiento y reproducción por la generación y disposición de un ingreso colectivo. Si antes el proceso migratorio se iniciaba para emprender una nueva vida y ejercer el rol de proveedor de la familia desde la distancia, ahora adquiere una dimensión colectiva en la medida en que se involucra tanto a los miembros del grupo que se quedan como a los que se van (Martín Díaz 2012). A su vez, las migraciones influyen en las relaciones de género, ya sea afianzando las desigualdades y roles tradicionales, o bien desafiándolos. Cuando los roles de género no coinciden con los de la sociedad receptora puede surgir el conflicto, originando en algunos casos exclusión social y dificultando así, su proceso de integración.

En una sociedad capitalista como la que vivimos, la discriminación laboral de las mujeres constituye un mecanismo de gran utilidad para la reproducción del capital. Por ello, el aumento de la participación femenina en la fuerza de trabajo no es casualidad, ni se debe únicamente a las conquistas que han ido logrando las mujeres en este ámbito. También se debe al interés de las empresas y de otros sectores laborales por contratar mano de obra más barata y por tanto, preferir a las mujeres. Así, la creciente demanda que tiene la economía mundial de mujeres con escasos niveles de cualificación, se convierte en una de las razones que motivan la creciente feminización de las migraciones (Godoy 2007; Lexartza, Carcedo y Chaves 2013).

Las mujeres se ocupan principalmente de tareas para las que no se tramita permiso de trabajo ni alta en la Seguridad Social, como internas en un domicilio, cuidadoras de personas mayores y en la hostelería (Bravo y Caparrós 2015; Hernández 2015). El trabajo en el ámbito doméstico de la mujer inmigrante provoca que no desaparezcan las desigualdades de género en la sociedad de acogida, al reproducirse los roles domésticos entre hombres y mujeres, ya que lo que ocurre es que se produce la sustitución de unas mujeres por otras (Bastia 2014). La demanda laboral femenina se relaciona con la naturalización de tareas de mujeres, que son consideradas como mano de obra más dócil y barata que los hombres. (Canales y Zlolniski 2000; Bastia 2009; Lexartza, Carcedo y Chaves 2013; Hernández 2015). Los datos sobre el empleo de mujeres inmigrantes latinoamericanas corresponden a mujeres en alta laboral o con permiso de trabajo, por lo tanto, quedan sin contabilizar la mayoría dado que normalmente realizan estas actividades en la economía sumergida. A esto se añade que las condiciones laborales han empeorado con la crisis lo que 
provoca que incluso en alguna ocasión es la propia trabajadora la que ofrece trabajar por menos dinero, cuando hay mucha competencia (Bastia 2014).

Oso (2003) analizó las estrategias migratorias de mujeres ecuatorianas y colombianas en situación irregular a través de entrevistas principalmente a empleadas de hogar o trabajadoras en clubes o pisos de contacto (no todas prostitutas). La principal diferencia entre ambos grupos era que las empleadas domésticas normalmente tienen un compañero o marido que ha realizado el proceso migratorio con ellas y en el segundo grupo había una mayor presencia de madres solteras, separadas o divorciadas, cuyos hijos permanecen inicialmente en el país de origen. Oso (2008) analiza las transformaciones en las relaciones familiares en cuanto relaciones de género. La mujer migrante asume un rol tradicionalmente pensado en masculino por lo que la autora se plantea si realmente a través de la migración estas mujeres consiguen un mayor grado de emancipación, como jefas de hogares transnacionales. La mujer que inicia sola el proceso migratorio deja atrás una familia, que denominamos transnacional cuando tiene hijos, lo que motiva que la mujer, como señala Retamozo (2014) continúe representando el rol social que se reserva al género femenino, es decir, continúa en la esfera doméstica aunque ahora se perciba desde una óptica transnacional. Bastia (2014) señala que las desigualdades de género se producen en origen y en destino. En el país de origen la migración provoca una reorganización familiar, pero temporal, a la espera de que retorne la trabajadora inmigrante. Lagomarsino (2014) señala que las mujeres son criticadas tanto por dejar a sus hijos en la sociedad de origen como por intentar reunificar a la familia, pues las condiciones para los hijos en la sociedad de acogida no son las ideales. La mujer inmigrante se siente responsable de establecer una relación entre los dos países: culturalmente son las encargadas de mantener y transmitir las propias tradiciones a sus hijos y nietos a la vez que tienen que posibilitar el acceso a las nuevas del país receptor (Giró y Fernández 2004).

Las nuevas tecnologías permiten que una presencia de las madres en la distancia virtual y simbólica, y que sea una maternidad compartida (Pedone 2008; Hernández 2015). Para desempeñar el cuidado transnacional la mujer necesita tener controlados tres aspectos: a) los recursos materiales y culturales con que cuenta b) las redes familiares que quedan establecidas en su país de origen y c) el estatus legal de estas madres en España (Hernández 2015: 100).

Martín Díaz (2012) agrupa en dos las causas que motivaron la decisión de emigrar de las mujeres ecuatorianas entrevistadas: las mujeres que se marcharon por factores relativos a la crisis político-económica de su país de origen y las que lo hicieron porque tuvieron la oportunidad de hacerlo. Respecto a las razones de elegir España una parte destacada responde que por la imposibilidad de entrar en EEUU. EI 90\% de estas mujeres se resisten a descartar por completo el regreso, aunque lo dejen en suspenso temporalmente. También Hernández (2015) en el caso de las mujeres guatemaltecas apunta que emigran como respuesta a la crisis económica de su país. Su 
intención es quedarse en Europa y mantener estas relaciones transnacionales, ya que no ven posibilidad de reagrupación familiar debido a su situación laboral como empleadas domésticas internas y a la dificultad de cumplir con los requisitos jurídicos obligatorios para la reagrupación.

Grinberg y Grinberg (1996) hablan de rupturas identitarias para señalar que las migraciones constituyen cambios en la vida de las personas que pueden ser de tal magnitud que pongan en evidencia e incluso en riesgo, su propia identidad. Se produce una fractura de identidad, en la que el yo de la persona inmigrante que se ha constituido con la familia, las costumbres, las pautas culturales, la educación y todo lo aprendido de su entorno, tiene que cambiar (Sayed-Ahmad 2008a). Estas rupturas identitarias también se generan porque las concepciones y roles de género pueden ser distintos. En este sentido, Padilla (2007) señala que los inmigrantes tienen género, pertenecen a un determinado grupo étnico, a una clase social y se integran a una sociedad de destino también sexual y étnicamente estratificada. Las personas que migran lo hacen con su historia personal, sus experiencias y con expectativas sobre lo que las nuevas experiencias van a suponer en su vida y en la de los demás (Solís 2005).

Desde una perspectiva de género encontramos una triple discriminación en el caso de las mujeres: la de su condición de extranjera, la de su condición de mujer y la de su condición étnica (Bermúdez, 2004). La suma de estos factores sitúa a la mujer inmigrante en una posición inferior al resto de la sociedad y se convierte en un colectivo vulnerable.

Petrozzielo (2013: 44) representa gráficamente la construcción idealizada de la mujer migrante a la que ve como coordinadora de la vida familiar transnacional, remitente de remesas fiable, cuidadora, protectora y proveedora con todo su corazón, trabajadora, abnegada y altruista, prestataria confiable, con un pie aquí y otro allí.

Las redes migratorias tienen una gran influencia desde el inicio del proceso migratorio facilitando la salida y la llegada, participando en la financiación del viaje, gestionando documentación, proporcionando contactos y ayudando en la búsqueda de empleo y vivienda. Constituyen una fuente de información sobre aspectos económicos, sociales y políticos de la sociedad receptora (Malgesini y Giménez 2000; Canales y Zlolniski 2000; Martine, Hakkert y Guzmán 2000; Salazar 2008; Martín Díaz 2012). Pero además de apoyo estas redes pretenden controlar el comportamiento de las personas que las integran con el objetivo de establecer fuertes vínculos con la sociedad de origen (Martín Díaz 2012) y a la vez que son un instrumento facilitador también pueden provocar segregación, ya que los recursos y apoyos que aportan están principalmente vinculados con su grupo de referencia, lo que puede dificultar la cohesión y la integración con el resto. 


\subsection{Coste físico y emocional de migrar}

La migración tiene un gran impacto psicológico que afecta al bienestar emocional de las personas. Atxotegui $(2005,2008,2010)$ ha abordado de manera profunda el duelo psicoafectivo que supone la migración y sus consecuencias para la adaptación. El autor considera la inmigración como un acontecimiento de la vida que implica situaciones de cambio en siete duelos específicos relacionados con la familia, los amigos, la lengua, la cultura, la tierra, el estatus, el contacto con el grupo étnico y los riesgos físicos. Sayed-Ahmad (2008b: 64) señala que "Las mujeres inmigrantes pueden padecer más que los hombres situaciones de estrés y dificultades psicológicas, no por ser más débiles o tener menos recursos personales, sino por la posibilidad de sufrir peores situaciones sociales, económicas y laborales por su condición de mujer". Pero no todo tiene que ser negativo, Godoy (2007) señala que las migraciones pueden tener efectos liberadores en las identidades de género de las mujeres, por ejemplo, la falta de control directo de la familia de origen y mayores posibilidades de autonomía personal en la cultura de acogida.

Los costes emocionales y materiales no solamente afectan a la persona que migra sino, también, a su red familiar y social en el país de origen. La principal fuente de tristeza y dolor para una amplia mayoría de mujeres inmigrantes es la desestructuración familiar, sobre todo, cuando hay separación de hijos menores. Además, muchas de ellas trabajan como niñeras en el país de destino y sufren al no poder cuidar a sus hijos y cuidar a otros. En muchas ocasiones se arrepienten de haberlos dejado y sienten angustia y dolor por la separación, sobre todo cuando son pequeños. Aunque también sientan satisfacción por su capacidad de sacrificio y por el esfuerzo que hacen para obtener un mayor bienestar, además de que están convencidas de un reagrupamiento familiar próximo y de que cumplen con su responsabilidad como madres al enviar remesas para la alimentación y educación de sus hijos (Oso 2008; Sinquin 2008). El esfuerzo realizado para compaginar su trabajo fuera de casa con las tareas domésticas y el cuidado de la familia en el nuevo país, la soledad ante potenciales situaciones de malos tratos o el rechazo de la sociedad de acogida a aspectos socioculturales vinculados a su cultura de origen son otros factores con gran coste emocional y que afectan a su adaptación (Sayed-Ahmad 2008a). Hidalgo et al. (2009) señalan que el estrés y la soledad suelen ser estados muy frecuentes que sufren estas mujeres y que pueden derivar en cuadros depresivos y ansiosos e incrementar la posibilidad de riesgo social.

A este coste emocional podemos añadir la concepción cotidiana de la inmigración como un problema en los medios de comunicación que a menudo muestran a los inmigrantes como competencia en los empleos. Además de acusarles de generar costes excesivos para los servicios sociales y considerarlos una amenaza permanente para la estabilidad social y política del país. Tales sentimientos frecuentemente estimulan reacciones populares xenófobas y la aplicación de políticas nacionalistas (Martine, Hakkert y Guzmán 2000), cuando en realidad, gran parte de los migran- 
tes se insertan en los espacios que la población natural ya no quiere ocupar, sea por tratarse de trabajos duros o pesados, mal remunerados o de escaso prestigio social (Canales y Zlolniski 2000). Con respecto a las mujeres los medios de comunicación también favorecen la existencia de estereotipos, especialmente en la mujer latinoamericana, relacionados con cuestiones sexuales, de tradiciones y creencias en cuanto a salud, trabajo y familia.

La emigración no solo conlleva costes emocionales, también tiene repercusiones físicas en las mujeres, aunque, en contra de la opinión cotidiana de que los inmigrantes traen enfermedades, numerosas investigaciones avalan que inicialmente suelen tener mejor estado de salud que la población local. Aspecto lógico si consideramos la salud como uno de los factores que permite y favorece la realización del propio viaje migratorio. Una vez en el lugar de destino y debido a los cambios socioculturales y personales que sufren, sí puede provocarse un deterioro de su salud física y emocional (Burgos y Parvic 2011). Bermúdez $(2004,2006)$, avala con su investigación que la morbilidad más usual entre la población femenina inmigrante es más de orden afectivo que orgánico y causada principalmente por las circunstancias de la emigración: su autoestima se ve disminuida y genera sentimientos de frustración y estrés emocional. Presentan dificultades de adaptación al medio que se manifiesta en miedos, temores y falta de control sobre su entorno. Respecto al ámbito de la salud es necesario destacar el importante papel que la mujer latinoamericana tiene como proveedora de conocimientos y cuidados que se transmiten de generación en generación entre las mujeres del grupo.

En este trabajo presentamos un estudio empírico de estas dimensiones de análisis de la inmigración con perspectiva de género a través del análisis de la experiencia de un grupo de mujeres latinoamericanas residentes en Salamanca.

\section{Metodología}

Esta investigación se desarrolla siguiendo un modelo cualitativo, con enfoque de género en el que hemos realizado un estudio de casos mediante entrevistas en profundidad a 14 mujeres de origen latinoamericano, entre 24 y 60 años, residentes en Salamanca desde hace más de 2 años (Tabla 1). La selección de las participantes comenzó en una asociación dedicada a la promoción de la salud de las mujeres inmigrantes, utilizando el método de bola de nieve. 
TABLA 1: Perfil de las informantes

\begin{tabular}{|c|c|c|c|c|c|}
\hline Informante & Edad & $\begin{array}{c}\text { Estado } \\
\text { civil }\end{array}$ & $\begin{array}{c}\text { País de } \\
\text { origen }\end{array}$ & $\begin{array}{c}\text { Año } \\
\text { migración }\end{array}$ & Ocupación \\
\hline $\mathbf{1}$ & 34 & Soltera & Argentina & 2001 & $\begin{array}{c}\text { Cuidadora de personas } \\
\text { mayores }\end{array}$ \\
\hline $\mathbf{2}$ & 34 & Casada & El Salvador & 2014 & Desempleada \\
\hline $\mathbf{3}$ & 40 & Soltera & Ecuador & 2000 & Empleada de hogar \\
\hline $\mathbf{4}$ & 24 & Casada & México & 2010 & Empleada de hogar \\
\hline $\mathbf{5}$ & 25 & Soltera & Ecuador & 2008 & Desempleada \\
\hline $\mathbf{6}$ & 33 & Soltera & Argentina & 2006 & $\begin{array}{c}\text { Cuidadora de personas } \\
\text { mayores }\end{array}$ \\
\hline $\mathbf{7}$ & 26 & Soltera & Colombia & 2008 & Empleada de hogar \\
\hline $\mathbf{8}$ & 57 & Casada & Colombia & 1991 & Empleada de hogar \\
\hline $\mathbf{9}$ & 34 & Soltera & Colombia & 2014 & Médica \\
\hline $\mathbf{1 0}$ & 36 & Soltera & Ecuador & 2012 & Empleada de hogar \\
\hline $\mathbf{1 1}$ & 32 & Soltera & Colombia & 2008 & Empleada de hogar \\
\hline $\mathbf{1 2}$ & 32 & Casada & El Salvador & 2007 & Empleada de hogar \\
\hline $\mathbf{1 3}$ & 26 & Soltera & El Salvador & 2013 & Administrativa \\
\hline $\mathbf{1 4}$ & 33 & Casada & Colombia & 2008 & Médica \\
\hline
\end{tabular}

Fuente: Elaboración propia.

Las entrevistas seguían un guión semiestructurado que constaba de las siguientes unidades de análisis: a) Proceso migratorio: causas y expectativas previas y posteriores. Influencia de las redes locales e internacionales, b) Acceso al mercado laboral, c) La salud desde una perspectiva intercultural y de género, d) Roles y estereotipos de género y e) Participación en la sociedad de acogida, ocio y tiempo libre.

Las entrevistas fueron grabadas con el consentimiento firmado de las participantes y se asignó un código a cada entrevista para garantizar el anonimato. Se realizaron en espacios públicos, bares y parques, en los locales de la asociación y en las viviendas de las informantes. El espacio era elegido por la entrevistada para facilitar su comodidad. Las entrevistas eran individuales pero en dos ocasiones estuvo presente el marido de la entrevistada.

Para el proceso interpretativo hemos seguido las indicaciones metodológicas de Ortí (1995), Bernard (2006), Guber (2001), Dietz (2011), Ander-Egg (2003) y Díaz Rada (2006). Realizamos un análisis de contenido de la información obtenida en las entrevistas. A esta información añadimos los datos aportados por la observación participante y el diario de campo. Los pasos seguidos fueron: a) Transcripción literal de los discursos de las entrevistas b) Definición de ejes analíticos que nos permitían reducir la información a unidades de significado y c) Codificación e interpretación de los datos. 


\section{Resultados}

\subsection{El proceso migratorio: causas y expectativas previas y posteriores.}

Podemos diferenciar tres perfiles de mujeres inmigrantes: a) Mujeres casadas con hijos que emprenden el viaje solas buscando mejores oportunidades laborales y económicas y con expectativas de poder reagrupar a su familia, b) Mujeres solteras que realizan la migración para tener una nueva vida con mayor estabilidad económica y formar una familia y c) Mujeres que viajan acompañadas por su marido, que es quien tiene oferta laboral en España.

Una de las razones principales para emprender el proceso migratorio a España es la seguridad física. Todas ellas han vivido experiencias de violencia e incluso asesinatos de familiares o personas cercanas por parte de organizaciones violentas. Estas experiencias provocan miedo constante, por ellas mismas y por sus allegados, lo que aumenta la motivación para migrar a un destino en el que puedan sentirse más seguras.

"Algunos se vienen porque allá no se encuentra trabajo (...) pero mi historia es un poco diferente porque yo allá sí que tenía trabajo y al igual mi esposo, los dos estudiamos sistemas informáticos y los dos teníamos buenos trabajos. El problema es que en mi país están las maras y para nosotros...nosotros queremos un futuro mejor para nuestros hijos, entonces en mi país iba a ser bien difícil (...) Hay un patrón que tu sabes de qué mara son, si lleva un tatuaje así y ya sabes y tienes que irte para otro lado, literalmente, cambiar de calle porque si te los enfrentas te matan por un celular... Entonces, es así, te matan por cualquier cosa, es muy fácil" (Informante 2).

A la hora de decidir el país de destino, las redes locales se convierten en un factor fundamental ya que son la fuente principal de recursos para su integración inicial, proporcionando información laboral, sobre asociaciones, servicios sociales y la gestión del día a día. En todos los casos, las entrevistadas tenían algún conocido o familiar de su país de origen que había emigrado anteriormente a España. Esto les aporta mayor seguridad y el coste emocional que supone la separación de su país de origen no es tan fuerte, pues sienten que mantienen de alguna manera el contacto y su identidad. Esto motiva que las relaciones sociales sean principalmente con otras mujeres latinoamericanas que conocían previamente o que conocen a través de las asociaciones. En ellas encuentran un fuerte apoyo pues son mujeres que están viviendo el mismo proceso o lo han vivido recientemente.

El proceso migratorio de estas mujeres suele estar financiado en su totalidad o en parte por sus padres y/o otros familiares, que asumen los costes del viaje y los gastos iniciales al llegar. Esto supone un contrato informal que obliga a la mujer a ir devolviendo el dinero por lo que tienen un fuerte sentimiento de deuda y de res- 
ponsabilidad. Si hay problemas para encontrar trabajo se producen retrasos y puede aparecer sentimiento de fracaso, tanto en ella como en su familia y más aun si han dejado hijos con la familia.

"Les mando dinero cada mes a mis padres, no siempre puedo mandarles pero normalmente lo hago porque ellos nos ayudaron a pagar el viaje a España. Yo tengo que devolverles la deuda" (Informante 10).

Las expectativas respecto al proceso migratorio van cambiando en función de las experiencias vividas. La primera diferencia viene marcada por las características económicas y laborales que en parte están determinadas por el nivel de estudios y afectan a la cualificación del trabajo realizado. Las mujeres con estudios y trabajos cualificados se sienten ciudadanas españolas y creen que han tenido una buena integración en la sociedad de acogida a pesar de las dificultades encontradas al llegar. Perciben que el machismo en su país de origen está más presente en el día a día y, aunque en España también existe, no es tan visible. Son críticas con la situación de la mujer respecto al hombre tanto en la sociedad española como en la latinoamericana. No muestran mucho arraigo a la cultura de su país de origen y en la actualidad se sienten más identificadas con la cultura española.

"En mi país son bastante machistas y por lo que he visto aquí, hasta ahorita una tiene derecho tanto como un hombre. Es que allá se nota más la diferencia; el hombre es el que sabe $y$ no es así porque hay muchas mujeres inteligentes y por eso es mejor acá. Aquí, en mi campo que es la informática, se refieren a programador y a programadora, no solo en términos masculinos, sino que también se dice programadora. Aquí es simplemente más equilibrado, sabes, se trata de saber colocarse y no se trata del sexo" (Informante 2).

Por el contrario las mujeres con trabajos poco cualificados y pocos estudios no tienen sentimiento de integración, no se sienten españolas y no solamente por no tener regulación administrativa, sino porque perciben claras diferencias socioeconómicas y laborales respecto a las españolas. Eran conscientes de que el proceso migratorio implicaría adversidades, pero sus expectativas sobre el lugar de destino eran, en general, más positivas que las que han resultado ser. Muestran mayor arraigo a su cultura de origen y no mencionan en ningún momento diferencias de roles de género. El proceso de adaptación es lento y existe un sentimiento de vacío en el que la mujer inmigrante no se siente de ningún lugar, se produce un desequilibrio del sentimiento de identidad. Afirman sentirse más cómodas cuando se relacionan con otras inmigrantes latinoamericanas que han pasado por experiencias parecidas. Esto puede implicar un alejamiento de la sociedad de acogida, pues se excluyen de las redes locales de la población autóctona lo que puede suponer un impedimento para su adaptación.

"En la asociación he conocido a mis amigas que son estupendas y para mi ha sido de gran ayuda ir a la asociación. Antes íbamos cada semana pero ahora vamos 
cada quince días. (..) Me gustaría poder reunirnos más a menudo pero la asociación ahora también tiene otros grupos y más trabajo (...) Mis amigas que nos vemos en la Iglesia son latinoamericanas también, dos de Ecuador y una colombiana que también tienen hijos de la misma edad que mi niña, entonces juegan juntos y somos todos amigos" (Informante 3).

Otra de las razones por las que deciden emigrar a nuestro país son las mayores expectativas laborales a pesar de que las oportunidades en España hayan disminuido con la crisis. Sin embargo, sus expectativas se ven frustradas cuaando se han encontrado condiciones laborales precarias, bajos salarios y ausencia de contratos. Solamente dos informantes han emigrado con la seguridad de un trabajo al llegar a Salamanca; una como médico y la otra en una empresa de seguros. Las complicaciones y el lento proceso de tramitaciones burocráticas para la regulación y la homologación de los estudios cursados en su país de origen también suponen una barrera de acceso al mercado laboral.

Los problemas laborales repercuten directamente en el envío de dinero a su familia; no pueden enviar nada o no en la cuantía suficiente. Esta situación también complica su intención de reagrupación familiar ya que disponen de escasos recursos económicos para financiarla. Su salud emocional se resiente al ver que sus propósitos no se cumplen como pensaban y aumenta su estrés: necesitan conseguir dinero con rapidez. No hemos detectado casos de prostitución pero si de acceso a empleos relacionados con tareas domésticas en condiciones muy precarias que se ven obligadas a aceptar como algo temporal porque las reporta dinero rápido.

La mayoría de las mujeres tienen intención de permanecer en España a pesar de las dificultades laborales y económicas que padecen. Para la mayoría de las mujeres el hecho de regresar supondría un fracaso y una decepción para ellas y para sus familiares, por la responsabilidad de triunfar para no sentirse fracasadas y avergonzadas. Esto implica, como hemos señalado, que el estrés se multiplique al esforzarse para conseguir recursos económicos y que su salud física y mental se resienta. El resto de mujeres se quedan por las razones ya expuestas: disponen de trabajo remunerado y lo necesitan para seguir enviando dinero, por la seguridad y por las mayores oportunidades de un futuro mejor para sus hijos.

"Allí me preocuparía por los estudios de la niña, la seguridad de la niña. Aquí no hay trabajo, a ver si me explico pero es que Méjico está hecho una guerra ... y es que yo me acuerdo que antes hace cinco años no era así, es que va empeorando, sí que había robos, había violaciones como en cualquier país grande ... pero en esta cantidad no mataban a la gente como ahora la matan y los dejan tirados como perros. (...) Y muchos se meten en el narcotráfico, mi primo no descarto que este metido en eso (...) Así que no me iría a vivir a mi país de nuevo y menos ahora con la niña" (Informante 4). 


\subsection{La mujer inmigrante en el ámbito laboral}

De las mujeres entrevistadas, once trabajan como cuidadoras de personas mayores o de niños y como empleadas de hogar (todas han trabajado en ambos empleos), dos son médicos pero solo una de ellas trabaja como tal (el contrato de la otra acababa de terminar) y otra es administrativa. Todas han trabajado en más de un empleo diferente. El acceso a estos empleos suele ser a través de redes locales y de instituciones sociales como Cruz Roja y Cáritas, donde les proporcionan orientación laboral e información sobre ofertas de trabajo (mayoritariamente relacionadas con la realización de tareas domésticas).

“En Cruz Roja me dijeron de esta oferta de trabajo para limpiar la casa a esta señora" (Informante 3).

"Mi sobrina que vino antes que yo a España conocía a mucha gente y me presentó a una señora que necesitaba a alguien para trabajar para ella en su casa" (Informante 8).

Como hemos señalado, tienen muchas trabas burocráticas para que sus estudios sean reconocidos en España, lo que también retrasa su acceso a ofertas laborales de mayor cualificación:

"Como mi cuñado ya lo había hecho sabía qué papeles tenía que entregar para la homologación de mis estudios. Pero tuvimos que estar esperando hasta que la universidad de allá nos lo compulse y mi papá nos lo envió para acá, pero se tarda mucho, se tarda más de un año. Y como yo no tenía NIE, obviamente no podía hacer nada, entonces tuve que esperar hasta que me dieran mi NIE para poder empezar los trámites de homologación. Es complicado" (Informante 2).

Ocho de las entrevistadas han relatado experiencias discriminatorias en el ámbito laboral por ser inmigrantes latinoamericanas; diferencias en los salarios, comentarios xenófobos entre los compañeros de trabajo y ofertas de trabajo específicamente dirigidas a mujeres españolas y a las que no pueden optar.

"Tuve un problema con un camarero que era muy racista, muy racista. Yo nunca contestaba nada para no tener problemas pero llegó el día que ya te machaca tanto que le respondí y vino a pegarme. Y entonces yo denuncié a él y él era el chupamedias, como se dice, del jefe, entonces de ahí comenzaron a no pagarme y hacer que yo me sintiera mal para que me fuera. Pero como estaba afiliada a Comisiones Obreras le consulté al abogado y me dijo no, estos lo hacen para que te vayas, aguanta ahí, pero digo jope aguantar todo esto... nadie me hablaba. Terminamos en el juicio, y nada, me pagaron cuando a ellos les pareció" (Informante 3$)$. 


\subsection{La salud desde una perspectiva intercultural y de género}

Ante cualquier síntoma y malestar, tanto físico como emocional, que no implique gravedad (estreñimiento, vómitos, dolor de cabeza, ansiedad, nervios) lo primero que hacen es preguntar a sus madres. Son ellas las que transmiten sus conocimientos sobre remedios naturales. En el caso de que estas mujeres inmigrantes tengan hijos utilizan estos mismos remedios cuando son ellos los que están enfermos. Transmitiéndose así el conocimiento de generación en generación y a pesar de la distancia y de que en muchas ocasiones las plantas que necesitan no están disponibles en España, por lo que tienen que enviárselas, con los gastos que esto origina.

"Mi madre conoce muchos remedios con distintas plantas que tenemos, aunque aquí es más difícil encontrarlas y algunas no existen aquí. Yo muchas veces me tomo unas infusiones que me enseño ella cuando me duele la barriga o tengo ansiedad" (Informante 6).

Comienzan haciéndose un autodiagnóstico tal y como harían sus madres, a partir de los síntomas que tienen y se aplican el tratamiento que consideran oportuno, especialmente en los embarazos y el cuidado de los niños.

"Me dolían los pechos así como cuando tuve a mi primera niña y llamé a mi madre y le dije: mami, ¿cómo se sabe cuándo una mujer está embarazada? Cogerse el pulso o verse los pezones o verse los ojos, si los ojos están tristes y los labios resecos es porque estás embarazada. Quién está embarazada me dijo mamá. $Y$ yo le dije: una amiga. $Y$ me dijo: dile a tu amiga que coja un vaso y en ayunas meta su primer pis y meta una aguja sin que nadie la haya usado y si la aguja sale negra; está embarazada. Y yo hice la prueba y cuando me levanté la aguja estaba negra, entonces ya me hice lo del pulso y tenía dos pulsos, y mamá ya nos enseñó que tenía que tener dos pulso, uno lento y otro más rápido. Me fui a la ducha y me miré los pezones y estaban poniéndose marroncitos." (Informante 3).

La religión tiene una importante presencia en el ámbito de la salud y la enfermedad. Hay una fuerte tradición de creencias relacionadas con el nacimiento y la muerte. La procreación es concebida como una bendición de Dios y como tal debe ser aceptado. El final de la vida también está muy ligado a la creencia divina y marca claramente los protocolos de luto que deben seguirse. Las referencias a Dios y otras creencias religiosas son constantes:

"Yo llevaba el parche para no tener hijos pero si Dios quiere darte hijos, te da la bendición y te los da" (Informante 3). 


\subsection{Roles y estereotipos de género}

Las tareas domésticas están feminizadas dando por sentado que son responsabilidad de la mujer. A las labores que ejecutan los hombres, como la organización de las cuentas y los gastos de la vivienda, aunque sean mínimas, se les otorga mayor importancia para el bien común. Si puntualmente ellos hacen alguna actividad que sienten como responsabilidad de la mujer, por ejemplo, cocinar algún día, se entiende como un "extra" de trabajo y se alaba más. Las principales responsabilidades de los hombres suelen estar relacionadas con los arreglos de la casa o cuando se requiere fuerza física.

"Las tareas domésticas las hacemos la que pueda, entre mi madre y yo nos las repartimos y por ejemplo las terrazas lo hace él, cosas más pesadas, de fuerza, de hombre, por ejemplo si se nos rompe la ventana él lo arregla o si se atasca el lavaplatos también lo arregla, porque yo.. Él es el manitas de la casa" (Informante 14).

Asimismo en dos de las entrevistas se han relatado situaciones de violencia de género. En ninguno de los casos se había puesto denuncia, aunque afirmaban seguir teniendo miedo por encontrarse con esos ellos. Una de las mujeres relató sus vivencias en uno de los episodios de violencia y el miedo persistente que continúa:

"Nos pusimos todas a bailar cuando sentí que alguien me agarró del brazo y me arrastró y yo no podía verle bien la cara quien era y era el padre de mi hija. Mi prima y las amigas de mi prima vinieron tras de mí y gritando que qué pasaba y él arrastrándome, y yo le decía: suéltame, suéltame, que es el cumpleaños de mi prima. Mi prima nunca se ha puesto enfadada pero en ese momento le dijo: porque de una puñetera vez no la dejas en paz! ¡Estás con mujeres, estás con una mujer por qué no la dejas en paz! Y mi prima se fue a una cabina porque ella no tenía móvil, entonces ella dijo que llamaría a la policía y él me soltó pero me dejo todo un moratón aquí"; "Al llegar a casa ya me estaban timbrando y quién era, era él, sabía todos los movimiento míos, todo, era una pesadez"; "Yo ya siempre he tenido miedo por si me lo encuentro otra vez" (Informante 3 ).

También ponen de manifiesto que sienten hacia ellas una consideración sobre su sexualidad diferente a las españolas, los hombres piensan que son más cercanas, cariñosas y mucho más dispuestas a mantener relaciones sexuales:

"La gente tiene adquirido que como tú eres de otro país pues a lo mejor sexualmente eres más fácil pues porque tiene la idea que la gente de otro país es como más cariñoso y por eso tienen acceso a un derecho sexual. Y a mí también me pasa, que por ser de otro país tiene derecho a más cosas, o sea como mujeres, por parte de los hombres" (Informante 13). 
Los estereotipos hacia la mujer latinoamericana provocan que doce de ellas se hayan sentido discriminadas por su origen latino.

\subsection{Participación en la sociedad de acogida, ocio y tiempo libre}

Todas las mujeres entrevistadas sienten que disponen de poco tiempo libre y el que tienen lo utilizan principalmente para las tareas domésticas, el cuidado de los hijos y realizar actividades junto a sus parejas, normalmente decididas por ellos, como por ejemplo ver el fútbol. Relacionan el ocio con el desempeño de tareas diarias fuera del ámbito laboral y realizan solas muy pocas actividades, normalmente acudir a alguna asociación de inmigrantes o religiosa. La iglesia supone un importante apoyo principalmente para las que no tienen estudios y trabajos cualificados. La religión tiene una fuerte influencia en sus países por lo que continuar realizando sus prácticas religiosas las permite mantener su identidad. Sin embargo, observamos un claro rechazo por parte de las informantes con estudios superiores hacia las creencias religiosas que se practicaban en su país de origen.

"Hoy por la tarde vamos a la de las monjitas, allí voy a aprender más sobre la biblia y sobre el evangelio" (...) Vamos las dos juntas, con mi hija, si, siempre. (...) $Y$ también vamos a ver al Padre... de la Iglesia... que nos reunimos una vez al mes" (Informante 3).

Una parte de su escaso tiempo de ocio lo dedican a realizar actividades de grupo con otras personas de su país de origen; celebrar fiestas regionales, comidas y especialmente actividades vinculadas a bailes latinos que son muy demandadas (cumbia, salsa, bachata).

En cuanto a la participación política, las mujeres sin estudios y con menos recursos económicos no tienen ningún interés ni participan en asuntos políticos, ni en España ni tampoco participaban en su país. La falta de regulación administrativa es otra limitación para su implicación en los asuntos políticos, principalmente por no poder votar.

"En el 15M acampé y había gente con distinta ideología y antes trabajaba en actividades del partido comunista pero porque mi novio era de ese partido pero participaba sin más, no comprometidamente, y en el 15M conocí a gente que pensaba como yo pues ahí descubrí que había lugar donde podía desarrollar uno su ideología" (Informante 1).

\section{Discusión y conclusiones}

El proceso global de feminización de la inmigración afecta también a España y concretamente en la ciudad de Salamanca en la que hemos realizado nuestro traba- 
jo de campo, también predominan las mujeres latinoamericanas, que son más del doble que los hombres. Responden a tres perfiles; mujeres casadas y con hijos que emprenden el viaje solas, mujeres solteras y sin hijos y mujeres que viajan acompañadas por su marido. Esto se aleja del perfil tradicional de mujer inmigrante, que era acompañante de un hombre. Estos cambios provocan que las migraciones surjan como una estrategia del grupo doméstico y la familia adquiera una perspectiva transnacional, que debe considerarse desde un enfoque de género como indican numerosos trabajos (Pedone 2002; Bermúdez 2004; Canales 2008; Padilla 2013; Bastia 2014; Bravo y Caparrós 2015; Hernández 2015).

La decisión de migrar y cómo hacerlo se toma en el seno del grupo doméstico, involucrando tanto a la mujer que emigra como al resto de los familiares que se quedan (Canales y Zlolniski 2000; Bastia 2009; Bravo y Caparrós 2015). Todas las mujeres entrevistadas han contado con la ayuda económica de su familia para iniciar el proceso migratorio, por lo que tienen hacia ellas un claro sentimiento de responsabilidad y de deuda.

Entre las razones por las que emprender el proceso migratorio destacan la búsqueda de una mayor seguridad, huyendo de experiencias de violencia, y mejores oportunidades laborales y económicas. Estudios anteriores señalaban como razón principal la situación de crisis económica y política en sus países de origen (Martín 2012; Hernández 2015), pero no la búsqueda de mayor seguridad física. Se deciden por venir a España y a Salamanca por la influencia de las redes migratorias locales que proporcionan contactos e información sobre el lugar de destino. Todos los casos analizados tenían algún familiar o conocido de su país que había emigrado anteriormente a Salamanca, aspecto que se confirma numerosos estudios anteriores (Malgesini y Giménez 2000; Canales y Zlolniski 2000; Martine, Hakkert y Guzmán 2000; Salazar 2008; Martín Díaz 2012). Esto les aporta mayor seguridad y menor coste emocional, al estar en contacto permanente con personas de su grupo de referencia, permitiendo mantener una conexión de valores comunes y un sentimiento de identidad, como también señalaban Martín (2012) y Martine, Hakkert y Guzmán (2000). Sin embargo, también puede convertirse en un mecanismo de segregación pues dificulta sus relaciones con mujeres salmantinas.

Sus expectativas previas al viaje eran más positivas de lo que después fueron al llegar. El proceso de adaptación es lento y señalan que al principio no se sienten de ningún lugar, ni de allí ni de aquí. Se produce un desequilibrio en su identidad y una ruptura identitaria, como definen Grinberg y Grinberg (1996), Sayed-Ahmad (2008) y Solís (2005).

Los estereotipos y las desigualdades de género puede influir desde la toma de decisión de migrar hasta su adaptación en el país de acogida, en función de los posibles cambios en los roles y en las relaciones de género que se vayan produciendo. Como señalan Bastia (2014) y Retamozo (2014) las desigualdades de género se van 
a producir en origen y en destino y la mujer continúa representando el rol social que se reserva al género femenino. En este sentido, las mujeres entrevistadas se sienten en una posición inferior por su condición de inmigrantes, y más aún por ser latinoamericanas. Continúan representando en España el mismo papel de mujer y madre: cuidadoras de los hijos, encargadas de las tareas domésticas y con un papel secundario en la organización económica de la familia. Ellas mismas otorgan mayor importancia a las actividades vinculadas a la organización familiar que realizan sus maridos. En el ámbito laboral se sienten discriminadas por las diferencias salariales respecto a los hombres y por los comentarios xenófobos de algunos compañeros. A pesar de los problemas las mujeres con estudios y trabajos cualificados se sienten integradas y perciben que el machismo es más fuerte en sus países de origen aunque en el tema de la igualdad de género señalan que queda mucho por hacer tanto allí como en España.

Respecto a los perfiles de mujeres inmigrantes en relación a su acceso al ámbito laboral en el lugar de destino se ha dividido en dos grupos, las que tienen estudios superiores y las que no. Las primeras tienen mayor facilidad para acceder a trabajos más cualificados mientras que las que no disponen de estudios suelen acceder a trabajos de baja cualificación y en condiciones de precariedad laboral. Normalmente ocupan puestos de trabajo relacionados con las tareas domésticas, ya sea como cuidadoras de ancianos y niños o como empleadas de hogar. Esto se refleja en diferentes investigaciones como las de Canales (2008), Solé (2009) y Bastia (2009).

Aun a pesar de las dificultades económicas y laborales que padecen siguen pensando permanecer en España e intentar mejorar su bienestar y el de su familia, pues regresar supondría un fracaso y una vergüenza y además piensan que están mejor aquí. Aspectos que también constatan autores como Hernández (2015) y Martín (2012).

Desde los momentos iniciales estas mujeres tienen que enviar dinero a sus familias para subsanar la deuda en el caso de que hayan recibido dinero para el viaje, $y$ también para el mantenimiento de la familia que queda allí. Esto se refleja en trabajos anteriores como los de Canales (2008), Oso (2006) y Pedone (2002) que afirman que las expectativas de contribución al mantenimiento de la familia están ligadas al género e influyen a la hora de plantearse la migración.

Es significativo el coste emocional que supone la migración para estas mujeres, que dejan atrás su país y a su familia y tienen que afrontar una nueva vida en un lugar desconocido. Se sienten responsables de lo que pasa allí y aquí, lo que incrementa su estrés. Estos cambios son recogidos en numerosos trabajos como los de Atxotegui (2008, 2010), Sayed-Ahmad (2008), Hidalgo et al. (2009) y Sinquin (2008).

Cabe mencionar el perfil de estas mujeres como principales transmisoras de cultura de generación en generación, de manera que sus creencias y tradiciones son transmitidas a sus hijos mediante la continuación de la práctica de estas en el lugar de destino 
y en su día a día: llevándoles a la Iglesia, enseñándoles bailes regionales, celebraciones y fiestas tradicionales o transmitiéndoles conocimientos relacionados con la manera de afrontar la salud y la enfermedad. Como señalan Giró y Fernández (2004) la mujer inmigrante se siente responsable de establecer una relación entre los dos países.

Como hemos señalado, estas mujeres plantean su intención de permanecer en España a pesar de que podemos concluir que son varias las dificultades a las que tienen que enfrentarse cotidianamente:

- El estrés emocional que provoca el proceso migratorio.

- Situaciones de precariedad laboral, con ausencia de contratos y bajos salarios.

- Falta de contacto con la población de acogida, relacionándose mayoritariamente con otras redes locales principalmente de su país de origen.

- Existencia de estereotipos y prejuicios de género que la posiciona en un nivel inferior respecto a las mujeres españolas.

- Ausencia de sentimiento de integración en la sociedad de acogida

- Presencia de contextos de violencia de género

Esto nos lleva a reflexionar sobre la necesidad de tomar conciencia de la incorporación plena y sin estereotipos de las mujeres inmigrantes a nuestra sociedad, teniendo en cuenta que forman parte de las dinámicas sociales, laborales, económicas y culturales. Por ello, es fundamental el trabajo dirigido a conseguir el empoderamiento de este colectivo, así como de realizar estudios que reflejen las experiencias y realidades que viven estas mujeres. La discriminación hacia las mujeres es evidente en el ámbito laboral y en la participación en la sociedad en su conjunto.

La limitación fundamental de este trabajo está en el número de casos presentado, aunque a la vez esto puede considerarse una ventaja de cara a la profundización en las narrativas de las mujeres informantes.

\section{Bibliografía}

Ander-Egg, E. 2003. Métodos y técnicas de investigación social. Buenos Aires: Lumen.

Anteby-Yemini, L., Baby-Collin, V., Mazzella, S., Mourlane, S., Parizot, C. Regnard, C. y Sintès, P. dir. 2014. Borders, Mobilities and Migrations: Perspectives from the Mediterranean, XIX-XXIst Century. Brussels: Peter Lang.

Atxotegui, J. 2005. “Estrés límite y salud mental: el síndrome del inmigrante con estrés crónico y múltiple (Síndrome de Ulises)." Revista Norte de Salud 21(5): 39-53.

Atxotegui, J. 2008. "Duelo migratorio extremo: El síndrome del inmigrante con estrés crónico y múltiple (Síndrome de Ulises)." Revista de Psicopatología y salud mental del niño y del adolescente 11: 15-25. 
Atxotegui, J. 2010. “Características de los inmigrantes con síndrome de estrés crónico del inmigrante o síndrome de Ulises". Revista Norte de Salud Mental 37(8):23-30.

Bastia, T. 2009. "La feminización de la migración transnacional y su potencial emancipatorio". Papeles 104: 67-77.

Bastia, T. 2014. "La reproducción de las desigualdades de género en origen y en destino: un estudio transnacional a partir de las migraciones bolivianas". Papeles del CEIC, año 2, Universidad del País Vasco. Consulta 24 de mayo del 2016 (http://dx.doi.org/ 10.1387/pceic. 12982$)$

Belza, $M^{a}$ J. 2004. "Condiciones sociolaborales, conductas de riesgo y prevalencia de infecciones de transmisión sexual en mujeres inmigrantes que ejercen la prostitución en Madrid". Gaceta Sanitaria 18(3): 177-183.

Bermúdez, E. 2004. "Imágenes de la salud y enfermedad de las mujeres colombianas inmigrantes en España". Gerencia y Políticas de Salud 3(7): 78-100.

Bermúdez, E. 2006. Mujeres inmigrantes y salud: testimonios colombianos. Valencia: Universidad de Valencia.

Bernard, H.R. 2006. Research Methods in Anthropology. Lanham: Altamira Press (4 ${ }^{\text {th }}$ edition).

Bravo, L. y Caparrós, N. 2015. "Café y palabras. Las voces de las mujeres que cruzan fronteras". Cuadernos de Trabajo Social 28(2): 225-234.

Burgos, M. y Parvic, T. 2011. "Atención en salud para migrantes: un desafío ético". Revista Brasileña de Enfermagem 64(3): 587-591.

Canales, A. 2008. "Remesas y desarrollo en América Latina: Una relación en busca de teoría". Migración y desarrollo 11: 5-30.

Canales, A. y Zlolniski, C. 2000. "Comunidades transnacionales y Migración en la era de la Globalización". Simposio sobre Migración Internacional en las Américas, San José, Costa Rica: CEPAL, CELADE, OIM, 413-432.

Carrasco, C., Borderías, C. y Torns, T. eds. 2011. El trabajo de cuidados Historia, Teoría y Políticas. Madrid: Los libros de la Catarata.

Díaz de Rada, Á. 2006. Etnografía y técnicas de investigación antropológica. Madrid: UNED.

Giró, J. y Fernández, A. 2004. Mujeres inmigrantes. Invisibilidad y práctica cotidiana. Logroño: Instituto de Estudios Riojanos.

Gregorio, C. 1998. Migración femenina. Su impacto en las relaciones de género. Madrid: Narcea.

Godoy, L. 2007. "Fenómenos Migratorios y Género: Identidades Femeninas "Remodeladas"." Psykhe 16 (1): 41-51.

Grinberg, L. y Grinberg, R. 1996. Migración y exilio. Estudio psicoanalítico. Buenos Aires: Editorial Biblioteca Nueva.

Guber, R. 2001. La Etnografía. Método, campo y reflexividad. Bogotá: Grupo Editorial Norma.

Hernández, A. L. 2015. "Cuidados que cruzan fronteras: la colectivización de la maternidad en un contexto migratorio". Acciones e Investigaciones Sociales 35: 93-114.

Hidalgo, N., Peralta, M.I., Robles, H., Vilar-López, R. y Pérez-García, M. 2009. “Estrés y psicopatología en mujeres inmigrantes: repercusiones sobre la calidad de vida". Psicología Conductual 17: 595-607. 
Instituto Nacional de Estadística (INE). 2015. Estadística de Migraciones. Consulta 20 de diciembre del 2016. (http://www.ine.es/jaxi/menu.do?type=pcaxis\&path=\%2Ft20 $\% 2 F p 277 \&$ file=inebase $\& L=0$ )

Lagomarsino, F. 2014. "Familias en movimiento: más allá de los estereotipos de la maternidad transnacional". Papeles del CEIC 2(108).

Lexartza, L., Carcedo A. y Chaves, Mª J. 2013. "Mujeres centroamericanas en las migraciones. Una mirada alternativa frente un discurso homogeneizante sobre las migraciones." Centro Feminista de Información y Acción. Consulta 18 de noviembre del 2016. (http://www.cimacnoticias.com.mx/sites/default/files/Mujeres\%20centroamericanas $\% 20$ en $\% 20$ las \%20migraciones.pdf)

Malgesini, G. y Giménez, C. 2000. Guía de conceptos sobre migraciones, racismo e interculturalidad. Madrid: Los libros de la Catarata.

Martín, E. 2012. "Estrategias migratorias de las mujeres ecuatorianas en Sevilla: acumulación de capital social en tiempos de crisis". Migraciones internacionales 6(4):107-138.

Martine, G., Hakkert, R. y Guzmán, J.M. 2000. Aspectos sociales de la migración internacional: consideraciones preliminares. Revista Notas de Población 73: 163-193.

Oso, L. 2003. “Estrategias migratorias de las mujeres ecuatorianas y colombianas en situación irregular: servicio doméstico y prostitución en Galicia, Madrid y Pamplona". Facultad de Socioloxia-Universidad da Coruña. Consulta 25 de septiembre del 2016. (http://www.mmo.gr/pdf/library/Spain/laura_oso_en\%20espanol.pdf)

Oso, L. 2008. "Migración, género y hogares transnacionales". Pp 561-586 en La inmigración en la sociedad española: Una radiografía multidisciplinar, editado por J. García Roca y J. Lacomba. Barcelona: Ediciones Bellaterra.

Ortí, A. 1995. "La confrontación de modelos y niveles epistemológicos en la génesis e historia de la investigación social". Pp 87-99 en Métodos y técnicas cualitativas de investigación en Ciencias Sociales, editado por J.M Delgado y J. Gutiérrez. España: Síntesis Psicológica.

Orozco, M. 2006. Consideraciones conceptuales, retos empíricos y soluciones para la medición de remesas. Inter-American Dialogue, remesas y desarrollo. Centro de Estudios Monetarios Latinoamericanos. Consulta 4 de noviembre del 2016. (http://idbdocs. iadb.org/wsdocs/getdocument.aspx?docnum=35798861)

Padilla, B. 2007. La inmigración brasileña en Portugal: considerando el género en análisis. Observatorio de la Inmigración, Lisboa: ACIDI. 113-134.

Padilla, B. 2013. "Género y migraciones; nuevas reconfiguraciones y protagonismos de las mujeres latinoamericanas. A modo de introducción." Anuario Americanista Europeo 11.

Pedone, C. 2002. “El potencial del análisis de las cadenas y redes migratorias en las migraciones internacionales contemporáneas." Pp 223-235 en Actas del III Congreso sobre la inmigración en España (vol.ll). Contextos y alternativas, editado por F.J. García Castaño y C. Muriel. Granada: Laboratorio de Estudios Interculturales.

Pedone, C. 2008. "Varones aventureros" vs. "madres que abandonan": Reconstrucción de las relaciones familiares a partir de la migración ecuatoriana. Revista Interdisciplinar da Mobilidade Humana (30): 45-64.

Pérez Orozco, A. 2006. Perspectivas feministas en torno a la economía. Madrid: Consejo Económico y Social. 
Pérez Orozco, A. 2011. "Crisis multidimensional y sostenibilidad de la vida". Revista de Investigaciones Feministas 2: 29-53.

Petrozziello, A. 2013. Género en marcha. Trabajando el nexo migración-desarrollo desde una perspectiva de género. Santo Domingo (República Dominicana): ONU Mujeres.

Retamozo, P.T. 2014. La inmigración y la mujer. Universidad Santiago de Compostela. Consulta 26 de febrero del 2016. http://www.alice-comunicacionpolitica.com/files/ ponencias/610-F5417ead06101410853584-ponencia-1.pdf)

Salazar, M. 2008. "Espacios transnacionales: migración y globalización". Teoría de la Educación: Educación y Cultura en la Sociedad de la Información 9(2): 151-168.

Sayed-Ahmad, N. 2008a. "El proceso de adaptación y su impacto sobre la salud mental de las personas inmigrantes." Pp: 21-31 en Salud mental en la Inmigración, editado por N. Sayed-Ahmad et al. España: Escuela Andaluza de Salud Pública.

Sayed-Ahmad, N. 2008b. "La inmigración en la encrucijada de la adaptación". Revista Norte de Salud Mental 32: 61-70.

Sinquin, E. 2008. "El costo psicosocial de la migración en las familias de las comunidades de origen". Revista Interdisciplinar da Mobilidade Humana 6 (30): 99-111.

Solé, C., Parella, S. y Cavalcanti, L. coords. 2009. Nuevos retos del transnacionalismo en el estudio de las migraciones. Madrid: Observatorio Permanente de la Inmigración.

Solís, A.E. 2005. Estrategias y mecanismos para el afrontamiento psicológico de la experiencia migratoria: dilemas, costos y complejidades. Ponencia presentada en el Seminario-Taller Migración intrafronteriza en América Central, San José (Costa Rica). Centro Centroamericano de Población. Consulta 15 de marzo del 2016. http://ccp.ucr.ac.cr/ noticias/migraif/pdf/solis.pdf

Stefoni, C. 2011. "Migración, remesas y desarrollo: Estado del arte de la discusión y perspectivas". Polis (Santiago) 10 (30): 495-521. 


\section{comunitania}

REVISTA INTERNACIONAL DE TRABAJO SOCIAL Y CIENCIAS SOCIALES

INTERNATIONAL JOURNAL OF SOCIAL WORK AND SOCIAL SCIENCES

\section{ARTICULOS/ARTICLES}

Análisis de la empleabilidad de los trabajadores y trabajadoras sociales en la región de Murcia / Analysis of employability of social workers in the Murcia region

María del Mar Fernández Robles y Enrique Pastor Seller

Jóvenes NiNi. Nuevas trayectorias hacia la exclusión social / NEET. New paths towards social exclusion

Ana Cristina Ruiz Mosquera, María de las Olas Palma García y Juan Carlos Álvarez Cortés

Págs 39-49

Metodologías de intervención para la atención del conflicto: Retos y herramientas desde la experiencia de Trabajo Social en Colombia. Dialogo de saberes, intercambio de experiencias / Intervention methodologies for care in conflict situations: Challenges and tools from the experience of Social Work in Colombia. Dialogue of knowledge, exchange of experiences

Helena Neves Almeida y Bibiana Esperanza Chiquillo

El impacto de la dimensión transnacional en la acción colectiva dentro de los contextos migratorios / The impact of transnational dimension on collective action in migratory contexts

Sara de la Pinta Prieto

From charity to social development: associations and local government in the city of Segovia (Spain) / De la

caridad al desarrollo social: asociaciones y administración local en la ciudad de Segovia (España)

Rafael Acebes Valentín

Págs 81-103

Págs 105-119

La formación de los trabajadores sociales en Colombia: un dilema de competencias o mercado / Training of

social workers in Colombia: a dilemma of competences or market

Mónica Liset Valbuena Porras y Lina María Pinzón Rocha

Págs 121-135

Inmigrantes latinoamericanas en Salamanca: estudio de experiencias y casos / Latin merican women migrants in Salamanca: study of experiences

Lourdes Moro Gutiérrez, María Jesús Pena Castro y María Fiol Ruiz

Págs 137-157

From assistance to the exercise of new citizenships: challenges of Social Workers professional performance towards the post - conflict victims in Colombia / De la asistencia al ejercicio de nuevas ciudadanías: retos en la actuación profesional del trabajador social frente a las víctimas en el posconflicto en Colombia

Yuri Alicia Chávez Plazas y Alba Stella Camelo Mayorga

Artivismo como herramienta de transformación social: dos iniciativas en los barrios de La Latina y Lavapiés (Madrid) / Artivism as a tool for political transformation: two initiatives in the neighbourhoods of La Latina and Lavapies (Madrid)

Eva Aladro Vico, María José Cavadas Gormaz, Dimitrina Jivkova Semova, Graciela Padilla Castillo,

Roxana Popelka Sosa y Paula Requeijo Rey

Adopción y Difusión de Innovación Social en las Redes Sociales Virtuales / Adoption and Diffusion of Social Innovation on Social Network Services

Joaquín Castillo de Mesa

Multiculturalidad y Ciencias Sociales: El caso de Psicología / Multicultural and Social Sciencies: Psychology $\mathrm{M}^{a}$ Inmaculada López Núñez, Jose Manuel Velasco Retamosa, Jorge García y Susana Rubio Valdehita

Prostitución online Transgénero y Salud Pública. Un Estudio Netnográfico en Tenerife / Online transgender Sex Work and Public Health. A Netnographic Study in Tenerife

Belén Peyró Outeiriño, Miguel del Fresno García y Lianne Urada

\section{BESENAAS/REVIEWS}

Esther Raya Diez y Antonio López Peláez (coords.). 2017. Investigación y práctica en Trabajo Social. Cuestiones para una ciencia del Trabajo Social / Social Work Research and practice. Contributing to a science of social work (por Ana Belén Cuesta Ruiz-Clavijo)

Alfredo Hidalgo Lavié (coord.). 2017. Trabajo Social, historia y desafíos de una profesión / Social work, history and challenges of a profession

(por Jesús Manuel Martínez Serrano)

Págs 267-270

Alfredo Hidalgo Lavié, Ana Isabel Lima Fernández (coords.). 2017. Trabajo Social Sociosanitario. Claves de Salud Pública, Dependencia y Trabajo Social / Social Work \& Health. Keys of Public Health, Dependence and Social Work

(Por Francisco Estepa Maestre)

Gorjón, Francisco. 2017. Mediación, su valor intangible y efectos operativos. Una visión integradora de los métodos alternos de solución de conflictos / Mediation, its intagible value and operational purposes. An integrating vision of alternate methods of conflict resolution. Ciudad de México

(Por Carlos Miranda-Medina)

Joaquín Castillo de Mesa. 2017. El trabajo social ante el reto de la transformación digital. Big data y redes sociales para la investigación e intervención social / The social work facing the challenge of digital transformation. Big data and social networks for social investigation and intervention

(Por Mario Millán Franco) 